\title{
Clinical evaluation of a sub-lingual vaccine for prevention of exacerbations in COPD
}

\author{
P. D. Nadig', A. Haran², M. Shetty ${ }^{1}$ \\ ${ }^{1}$ Department of Pharmacology, Vydehi Institute of Medical Sciences and Research Centre, Bangalore, Karnataka, India, ${ }^{2}$ Department of \\ Pulmonary Medicine, Vydehi Institute of Medical Sciences and Research Centre, Bangalore, Karnataka, India
}

\section{A B S T R A C T}

Background: Lower airway bacterial infection is one of the major cause for exacerbation in COPD. Multicomponent vaccines derived from the various causative pathogens are shown to prevent the exacerbations. Aims and Objectives: The present study was carried out to evaluate the efficacy of sublingual vaccine (Ismigen) in preventing the exacerbations in COPD and to observe its tolerability. Materials and Methods: Twenty four COPD patients meeting the eligibility criteria were enrolled in the study. Ismigen was administered once a day sublingually for ten days a month for three consecutive months. They were observed over one year for exacerbations, hospitalisations, respiratory symptoms, lung function tests and adverse reactions. The mean scores of the parameters in the previous year were compared with that of the year following treatment. Students $t$ test and Chi- square test were used for analysis. Results: The mean number of exacerbations reduced from $6.79 \pm 3.51$ to $2.67 \pm 1.90(p<0.001)$ and the mean number of hospitalisations from $2.29 \pm 1.85$ to $0.67 \pm 0.87(p<0.001)$. There was no significant change in the respiratory symptom score and lung function test. Mild non-serious adverse event was reported by one patient. Conclusion: The results indicated that Ismigen could be an effective and well-tolerated add on therapy in COPD to reduce the frequency and severity of exacerbations.

Key words: Exacerbation, Infection, Sublingual, Vaccine

\section{INTRODUCTION}

Chronic Obstructive Pulmonary Disease (COPD) is among the top 10 contributors to global burden of disease. ${ }^{1}$ According to World Health Organisation (WHO) by 2030, this disease would become the fourth leading cause of death worldwide. ${ }^{2}$ Approximately 14.84 million Indians currently suffer from chronic obstructive pulmonary disease. $^{3}$

Acute exacerbations, characterised by worsening of respiratory symptoms beyond normal day to day variations necessitating change in medication, are common in COPD. ${ }^{4}$ The Global Initiative for Chronic Obstructive Lung Disease (GOLD) mentions that exacerbations and comorbidities contribute to the overall severity in individual patient. $^{5}$ COPD exacerbations are also associated with significant morbidity, health care cost and mortality. ${ }^{6}$
The most common cause for precipitation of an exacerbation in COPD is viral or bacterial infection. ${ }^{5}$ The organisms implicated are-Haemophilus influenzae, Streptococcus pneumoniae, Haemophilus parainfluenzae, Branhamellacatarrhalis, Pseudomonas aeruginosa, Moraxella catarrhalis, Staphylococcus aureus, Klebsiella pneumoniae. ${ }^{7,8}$

Influenza and Pneumococcal vaccines have shown to reduce the frequency of exacerbations and hospitalizations in COPD. ${ }^{9}$ However these vaccines do not cover the wide spectrum of causative bacteriae mentioned above. A randomised controlled clinical trial with vaccine containing Polyvalent Mechanical Bacterial Lysates (PMBL) from Streptococcus pneumoniae, Haemophilus influenzae, Moraxellacatarrhalis, Staphylococcus aureus, Streptococcus pyogenes, Streptococcus viridians, Klebsiella pneumoniae, Klebsiellaozaenaes has shown to reduce exacerbations, 
hospitalizations and antibiotic use when added to the regular treatment in $\mathrm{COPD} .{ }^{10}$ The vaccine was well tolerated except for mild adverse events like cutaneous eruptions and urological problems in some patients. ${ }^{11}$

Systematic reviews on trials with oral vaccines in COPD have shown that they reduce the number, severity, and duration of acute exacerbations. However, many of the primary trials on which they were based were small and methodologically flawed. ${ }^{12}$ The authors of these reviews suggested the need to have more number of trials before they could be considered as part of the routine clinical management of patients with COPD. Furthermore, there is not enough published data on clinical efficacy of polyvalent vaccines on Indian population. With this background the present study was intended to generate data on the efficacy and safety of this vaccine particularly with reference to Indian population.

The objective of the study was to evaluate the effect of Ismigen a PMBL sublingual vaccine on preventing the exacerbations in COPD and determine the adverse effects if any.

\section{MATERIALS AND METHODS}

The study was conducted in the department of Pulmonary Medicine of our institute after the approval of Institutional Ethics Committee of Vydehi Institute of Medical Sciences and Research Centre.(No.VIMS/IEC/50/10; dated $20 / 11 / 10)$. The study was carried out in accordance with the standard guidelines prescribed by Indian council of Medical research. It was conducted from Jan 2010 to Dec 2011.

COPD patients diagnosed as per GOLD guidelines, above 45 years of age with a history of at-least one or more exacerbations in the previous year, not involved in any other study and those willing to give written informed consent were included in the study. All the patients recruited were known cases of COPD who regularly came for follow up to our centre for the last 3-4 years. Episodesof worsening of cough and breathlessness with increase in quantity and purulent sputum, with or without other signs of infection that led a care provider to prescribe antibiotics or corticosteroids (or both) or that led to hospitalization were considered as exacerbations. Patients with co-morbid conditions like HIV, diabetes, tuberculosis, cancer, systemic fungal infections, on long term oral steroid therapy and patients with history of drug allergy were excluded.

After enrolment, a detailed history was obtained with regard to the duration and severity of illness, the frequency of exacerbations in the previous year, hospitalisation, medications, co-morbid diseases and personal habits.
The history of hospitalisation was confirmed with the hospital records. The patients were clinically examined and subjected for routine blood investigations, Chest X-ray and Spirometry.

They were managed with antibiotics or corticosteroids or both either as outpatient or inpatient depending on the severity. Onces table, they were prescribed Ismigen (Lupin $50 \mathrm{mg}$ ). The treatment schedule was one tablet per day to be taken sublingually on empty stomach with an instruction not to have food in the next one hour. The treatment was for 10 consecutive days. Patients were asked to report immediately if exacerbations or any adverse effects were observed. The course was repeated in the next two consecutive months. During this period, the patients continued the ongoing treatment for COPD. Patients were followed up on the first week of $2^{\text {nd }}, 3^{\text {td }}, 6^{\text {th }}, 9^{\text {th }}$ and $12^{\text {th }}$ month after initiation of treatment. They were also asked to bring the Ismigen strips during the follow up to check the compliance. Enquiry was made to elicit adverse effects.

At the end of one year all patients were asked to continue with their ongoing treatment for COPD. Patients were dropped from the study if there were severe adverse reaction to the drug or if they were non-compliant.

The outcome measures of efficacy were reduction in the number of exacerbations and hospitalisations, improvement lung function tests as compared to the previous year. Safety was assessed by the frequency and severity of adverse effects.

\section{Statistical analysis}

Descriptive statistical analysis was carried out in the present study. Results on continuous measurements were presented as Mean \pm SD and results on categorical measurements were presented in Number (\%). Significance was assessed at $5 \%$ level of significance.

Student t test (two tailed, dependent) and Chi-square/ Fisher Exact test were used to find the significance of study parameters.

\section{RESULTS}

One hundred and fifty patients met the inclusion criteria, out of which 80 were contacted. Informed consent was given by 29 patients. The remaining patients were reluctant to give consent as it was difficult for them to come for regular follow up.

There were 5 drop outs in the study who did not come for follow up for unknown reasons. The present analysis is done on the data obtained from 24 patients. 


\section{Demographic details}

All the patients who completed the study were above 50 years with mean age being $62.13 \pm 4.73$ years. There were two females and 22 males. The mean duration of COPD was 9.54 \pm 6.11 years. All the male patients were smokers. Duration of smoking in patients ranged from 11-40 years with a mean duration of $23.04 \pm 10.02$ years.

\section{Exacerbations}

The mean number of exacerbations reduced significantly after treatment $(\mathrm{p}<0.001)$ as shown in Table-1.

\section{Hospitalisations}

The number of hospitalisations as compared to the previous year reduced significantly post-treatment $(\mathrm{p}<0.001)$ as shown in Table 2.

\section{Pulmonary function tests}

As seen in Table-3, there was no significant change in the Forced expiratory volume at $1^{\text {st }}$ second(FEV1). FEV1 forms an important objective measurement of airflow limitation that is reproducible. A decrease in FEV1/FVC (forced vital capacity) ratio is considered as the first sign of developing airflow limitation. FEV1/FVC ratio showed some improvement which was statistically significant $(\mathrm{p}<0.05)$.

\begin{tabular}{|c|c|c|}
\hline & $\begin{array}{c}\text { In the year } \\
\text { before treatment }\end{array}$ & $\begin{array}{c}\text { In the year } \\
\text { following treatment }\end{array}$ \\
\hline $\begin{array}{l}\text { Mean number of } \\
\text { exacerbations } \pm S D\end{array}$ & $6.79 \pm 3.51$ & $2.67 \pm 1.90^{\star *}$ \\
\hline Inference & \multicolumn{2}{|c|}{$\begin{array}{c}\text { Mean number of exacerbations is } \\
\text { significantly less after treatment with } \\
t=6.196 ;{ }^{* *} p<0.001\end{array}$} \\
\hline
\end{tabular}

\begin{tabular}{|c|c|c|}
\hline Hospitalisations & $\begin{array}{c}\text { In the year } \\
\text { before treatment }\end{array}$ & $\begin{array}{c}\text { In the year } \\
\text { following treatment }\end{array}$ \\
\hline $\begin{array}{l}\text { Mean number of } \\
\text { hospitalisations } \pm S D\end{array}$ & $2.29 \pm 1.85$ & $0.67 \pm 0.8^{* *}$ \\
\hline Inference & \multicolumn{2}{|c|}{$\begin{array}{l}\text { Mean number of hospitalisations is } \\
\text { significantly less after treatment with } \\
t=6.065 ;{ }^{* *} p<0.001\end{array}$} \\
\hline
\end{tabular}

\begin{tabular}{|c|c|c|c|}
\hline PFT & $\begin{array}{l}\text { Before treatment } \\
\text { mean } \pm S D\end{array}$ & $\begin{array}{l}\text { After treatment } \\
\text { mean } \pm S D\end{array}$ & $P$ value \\
\hline FEV1 (\%) & $44.25 \pm 12.30$ & $47.63 \pm 16.49$ & 0.386 \\
\hline FVC (\%) & $65.13 \pm 20.07$ & $68.29 \pm 21.13$ & 0.486 \\
\hline FEV1/FVC (\%) & $65.79 \pm 9.05$ & $69.58 \pm 10.02$ & $0.031^{*}$ \\
\hline Inference & \multicolumn{3}{|c|}{$\begin{array}{c}\text { *Mean FEV1/FVC is statistically significant. } \\
\qquad<<0.05\end{array}$} \\
\hline
\end{tabular}

\section{Adverse events}

One patient developed ulcer in the sublingual region on the $5^{\text {th }}$ day of the first month of Ismigen administration for which oral multivitamin tablets were prescribed.

\section{COMPLAINCE TO MEDICATION}

All the patients were compliant to Ismigen.

\section{DISCUSSION}

The present study was conducted to evaluate efficacy of Ismigen in preventing the exacerbations in COPD and also to ascertain its safety. Efficacy was measured by comparing the number of exacerbations, number of hospitalisations, Respiratory symptom score and lung function tests before and after one course of Ismigen. Safety was measured by monitoring the occurrence of adverse effects.

Most of our patients were frequent exacerbators (more than 2 exacerbations per year). It was observed from the results of the study that there was a significant reduction $(70 \%)$ in the mean number of exacerbations. This was comparable to a study by Cogo $\mathrm{R}$ et al on 57 patients of COPD with at least one exacerbation over past 12 months. ${ }^{13}$ They evaluated the incidence of exacerbations following Ismigen treatment. The total number of exacerbations in the patients treated with Ismigen dropped to 34 compared to 85 episodes $(60 \%)$ recorded during the control period of the previous 12 months $(\mathrm{p}<0.05)$.

The economic burden of COPD exacerbations account for up to $70 \%$ of all direct costs associated with COPD and most of these costs are attributed to hospital care. The costs increase with the severity of the exacerbation. Reducing the frequency and severity of COPD exacerbations therefore not only retards the progression of the disease process but also reduces the economic burden of COPD for the patient significantly. ${ }^{14}$ In the present study the mean number of hospitalisations due to exacerbations reduced by $54.35 \%$. Therefore it implies that use of Ismigen could reduce the overall expenditure by minimising the patient admissions.

Respiratory function (FEV1) declines annually in the natural course of COPD. ${ }^{15}$ Our study observed that there was no change in the lung function tests. However, the FEV1/FVC ratio showed a statistically significant improvement which was clinically insignificant. Li J et al observed improvement in respiratory symptom scores compared with the placebo group in a controlled clinical trial of a similar bacterial lysate (OM-85BV) involving 90 patients under observation for one year. However not much improvement was observed 
in airflow limitation. The authors concluded that this was probably due to short course of the treatment. ${ }^{16}$

The above observations indicate that the given course of Ismigen may not have a direct impact on the underlying pathophysiology of the disease although it may slow down the progression of disease by controlling infections. A modification in the treatment regimen probably by repeated courses may be required to see pronounced effect on the respiratory symptoms and lung function tests.

There were no significant adverse drug reactions with Ismigen except for one non-serious mild adverse event that was managed symptomatically. The symptoms did not recur following treatment and the patients continued with Ismigen. These observations are similar to Soler et al who evaluated a vaccine containing same bacterial lysate in recurrent exacerbations in patients with COPD. ${ }^{17}$ However some studies have reported cutaneous reactions and urological problems. ${ }^{11}$ The vaccine is therefore well tolerated.

These preliminary observations suggest the need for randomised clinical trials comparing pneumococcal vaccine with polyvalent mechanical bacterial lysate like Ismigen to throw more light on use of prophylactic vaccines in COPD.

The study established that Ismigen could be an effective medication to reduce the exacerbations, thereby reducing the number of hospitalisations and economic burden to the COPD patients. The side effects reported were also minimal. Further studies with a longer course of treatment, with a placebo group is worth investigating.

The following were the limitations of the study:

- It is not a placebo controlled study which is an ideal clinical trial design,

- It had a small sample size,

- Did not explore the mechanisms of action.

A comparative trial with the current pneumococcal vaccine could have shown superiority or inferiority.

\section{ACKNOWLEDGEMENT}

The authors are thankful to the management for supporting the research work.

\section{REFERENCES}

1. https://www. health metrics and evaluation.org/gbd 2013 accessed on 02/01/2014.

2. World Health organisation. Chronic obstructive pulmonary disease (COPD); Fact sheetN³15, Reviewed October 2013.

3. Jindal SK, Aggarwal AN, Gupta D, Agarwal R, Kumar R, Kaur T, et al. Indian study on epidemiology of asthma, respiratory symptoms and chronic bronchitis in adults (INSEARCH). Int J Tuberc Lung Dis 2012;16:1270-1277.

4. Celli BR and BarnesP. J. Exacerbations of COPD. Eur. Respir. J. 2007;29:1224-1238.

5. Global Initiative for Chronic Obstructive Lung Disease. Global strategy for the diagnosis, management and preventionof Chronic Obstructive Pulmonary Disease, GOLD report 2013.

6. Vijayan. V.K. Chronic obstructive pulmonary disease. Indian J Med Res. 2013;137(2):251-269.

7. Patel I.S., Seemungal T.A.R, Wilks, M, Lloyd-Owen S J, Donaldson GC and Wedzicha J.A. Relationship between bacterial colonisationand the frequency, character, and severity of COPD exacerbations. Thorax. 2002; 57:759-764.

8. Papi A, Luppi F, Franco F and Fabbri LM. Pathophysiology of exacerbationsof chronic obstructive pulmonary disease. Proc Am Thorac Soc. 2006;3(3):245-251.

9. Varkey JB, Varkey AB, Varkey B. Prophylactic Vaccines in COPD: Influenza and Pneumococcal Vaccinne: An Additive Effect. Current opinion in pulmonary medicine. 2009; 15(2):90-99.

10. Cazzola M, Noschese $P$ and DiPerna F. Value of adding a polyvalent mechanical bacterial lysate to therapy of COPD patients under regular treatment with salmetrol/fluticasone. Therapeutic Advances in Respiratory Disease. 2009;3(2):59-63.

11. Steurer-Stey C, Bachmann LM, Steurer J, Tramèr MR. Oral purified bacterial extracts in chronic bronchitis and COPD: systematicreview. Chest. 2004;126(5):1645-1655.

12. Arandjus C, Black PN, Poole PJ, Wood Baker R andSteurer-SteyC. Oral bacterial vaccines for the prevention of acute exacerbations in chronic obstructive pulmonary disease and chronic bronchitis. Respir Med. 2006;100(10):1671-81.

13. Cogo R, Ramponi A, Giorgio S and Rippoli R. Prophylaxis for acute exacerbations of chronic bronchitis using an antibacterial sublingual vaccine obtained through mechanical lysis: a clinical and pharmacoeconomic study. Acta bio Medica. 2003; 74; 81-87.

14. Breunig IM, Shaya FT and Scharf SM. Delivering Cost-effective Care for COPD in the USA, Recent Progress and Current Challenges. Expert Rev Pharmacoeconomics Outcomes Res. 2012;12(6):795-808.

15. William Macnee in "Chronic bronchitis and emphysema" in: Anthony Seaton, Douglas Seaton Eds; Crofton and Douglas's Respiratory diseases Volume-1 Fifth Edition; Blackwell Science, India. 2004,626-627.

16. Li J, Zheng JP, Yuan JP, Zeng GQ, Zhong NS and Lin CY. Protective effect of a bacterial extract against acute exacerbation in patients with chronic bronchitis accompanied by chronic obstructive pulmonary disease. Chinese medical journal. 2004; 117(6):828-834.

17. Soler M, Mutterlein R and Cozma G. Double blind study of OM-85 in patients with chronic bronchitis or mild chronic obstructive pulmonary disease. Respiration. 2007;74:26-32.

\footnotetext{
Authors Contribution:

PN - drafted the protocol, reviewed the literature, collected the references and did the final editing of the paper; AH - supervised the whole study, monitored, helped in drafting the paper, collected references and managed the study subjects; $\mathbf{M S ~ - ~ c o l l e c t e d ~ t h e ~ d a t a , ~ c o l l e c t e d ~ t h e ~ i n f o r m e d ~ c o n s e n t ~ f o r m , ~ f o l l o w e d ~ u p ~ w i t h ~}$ patients and drafted the first version of the paper.

Source of Funding: Self and management, Conflict of Interest: None declared.
} 